\title{
Dynamic Models in Atmospheric Monitoring Signal Evaluation for Safety, Health and Cost Benefits
}

\author{
G. L. Danko ${ }^{1,2} \cdot$ W. K. Asante ${ }^{1}$ - D. Bahrami ${ }^{1} \cdot$ C. Stewart ${ }^{3}$
}

Received: 8 August 2018 / Accepted: 11 June 2019/Published online: 9 July 2019

(C) The Author(s) 2019

\begin{abstract}
It is prudent to interpret atmospheric monitoring signals in real time for checking the safe limits of the air conditions in underground mines. In gassy mines, real-time evaluation increases the safety of operations. In all mines, continuous monitoring and evaluation contributes to maintaining air conditions within healthy and safe limits. Signal interpretation for safety conditions in mines is difficult for many reasons. An increase in hazardous contaminant concentrations can be predicted by signal pattern recognition, root cause analysis of rapid changes toward deterioration, and forward prediction in time using algorithms and numerical models. The paper describes an early warning system for analyzing monitored signal patterns continuously in real time as well as forward predicting the various environmental and working conditions to recognize dangerous trends that may affect safety and health in underground mines. A dynamic, numerical ventilation model with heat and gas contaminant simulation components is used for the analysis of atmospheric data. Methods and test results are discussed with numerical examples for signal propagation prediction. Several mine examples are studied using controlled, synthetic data for malfunction simulations to evaluate time delays between the detection time of suspicious signal trends and the time of dangerous threshold crossing marking an accident scenario. Delay time is found in the order of $20 \mathrm{~min}$ in the examples, signifying the useful time period for preventive intervention between EWS warning and the likely breakout of a following accident.
\end{abstract}

Keywords Monitoring data evaluation $\cdot$ Mine safety and health $\cdot$ Accident prevention $\cdot$ Early warning system $\cdot$ Ventilation control . MULTIFLUX · Dynamic models

\section{Introduction}

The challenge addressed is to maintain and augment safety and health of the workers in the extractive industries characterized by fast-growing scales of operations and increasing mechanization, automation, and robotics. The rapidly shrinking workforce and the proportionally diminished direct human feedback may create new problems in safety and compliance lacking observation and first-hand information about the safety and health conditions in industrial settings. Mandated, pre-, and on-shift examinations [1] will become problematic in automated mines. It is necessary to

G. L. Danko

danko@unr.edu

1 Mining and Metallurgical Engineering Department, University of Nevada, Reno, NV, USA

2 Research Institute of Applied Earth Sciences, University of Miskolc, Miskolc, Hungary

3 Howden-Ventsim, Brisbane, Australia rely on the application of monitoring sensor networks and automatic evaluation of the signal streams for worrisome trends with fewer humans in the loop between problem detection and preventive management action for intervention. The ever stricter regulations for safety and health will require better ventilation design methods and model calibrations and such tasks will require the use of artificial intelligence (AI) and machine learning (ML) integrated in the real-time monitoring operation. For the evaluation of worrisome signal trends, signal evaluation will have to include forward predictions for forecasting future outcome possibilities for preventive measures if necessary. Such an early warning system (EWS) has been the subject of a technology concept investigation supported by the Alpha Foundation [2].

The focus area of this paper is the application of continuous atmospheric monitoring system (AMS) monitoring together with the use of dynamic simulation models and information techniques to develop EWS for improving mine safety, related to hazardous atmospheric conditions in a mine ventilation system. Significant improvements may be made in mine safety and health by the early recognition of hazards caused by heat, combustible gases, or the accumulation of poisonous gases. 
The recognition of safety hazards by manual evaluation is difficult because of the complex nature of information and the large amount of monitored data from measurements by atmospheric sensors such as air velocity, pressure, hazardous gas contaminants, and temperature. In order to recognize problem-causing trends, it is necessary to evaluate continuously measured data from the AMS for time-dependent variations.

It is difficult to foresee the possible outcomes of intertwined signatures of various problems by continuous human observation. Information technology (IT) tools with ML and AI are necessary in addition to the mine-wide monitoring system data and the dynamic mine ventilation model (DMVM) components in the EWS design [2]. It has been recognized that information and modeling technologies must accompany the AMS network applications [3]. The response to any change in the operation conditions, either man-caused or natural, must be interpreted by the EWS to avoid false alarms but not to miss the evolution of an impending event of safety hazard.

For example, a steady, continuous methane concentration measurement together with a sharp drop in barometric pressure from the AMS sensors may be a case for worry in future time due to pressure-induced methane increase from the coal seam or the gob. Such a future increase can only be foreseen by a DMVM with its air parameter predictor component. The effects of barometric pressure variation has been well recognized and studied by numerical models [4-7]. Such timedelayed trends, however, cannot be seen from the raw measurement data which refer to the past time period only.

Methane is one of the most dangerous gases in mines $[1,8]$ and must be kept in the focus of the EWS functions. Methane emission models are published extensively [4, 5, 9-14]. Computational fluid dynamics (CFD) models such as Cradle [15] and [16]or Porous-Media Transport (PMT) models, e.g., NUFT [17] and TOUGH2 [18] may be used for prediction of methane release from the strata or the gob area. However, the CFD and PMT models are both computationally extensive with a slow response time for real-time, forward prediction simulations in the EWS application. Either a transport network solver configured for the gob, or a fast-running, surrogate model such as a Numerical Transport Code Functionalization (NTCF) accelerator $([19,20], 2013)$ or a Neural Network (NN) model [10] is necessary to meet the demand for fast computational response time. Other gas components in the mine atmosphere are also predicted as the function of the mining conditions in the DMVM.

The necessary elements of the EWS are the application of $\mathrm{AI}$ and $\mathrm{ML}$ for AMS signal processing together with fast-running, real-time, ventilation and contaminant transport models to support mine management in recognizing warning trends. A new type of DMVM is needed to represent the mine for regular operations and produce the expected reference for continuous, automatic comparison with the AMS data stream.
The DMVM may stem from [21]which demonstrated the display of real-time data within simulated dynamic modes using LiveView ${ }^{\mathrm{TM}}$ [22]. Other ventilation software including [21] Vuma $^{\mathrm{TM}}$ [23], or MULTIFLUX ${ }^{\mathrm{TM}}$ [24-27] may also be applicable for DMVM. A new, computational energy dynamics (CED) solution technique is implemented in MULTIFLUX [28] for further increasing computational efficiency, making it preferable for real-time ventilation analysis and control applications such in the EWS.

Safety improvement can be achieved by the recognition of early trends which indicate potential safety hazards. Measures must be taken in adequate time to counteract the interplay of many causes leading to an accident. The study of past mine accident scenarios related to mine ventilation [29] shows that the accidents were preventable. However, worrisome signs of events must be recognized during their evolution before the chain reaction of many events may trigger a catastrophic accident. For such a complex analysis, new methods are needed using computational model prediction together with the evaluation of the monitored data from the AMS by IT tools.

An additional goal of the EWS system is to support optimum ventilation control assistance. Such benefits include a report for safety factor variations with time at critical locations for evaluating health conditions and report the occurrence of under- or over-ventilation for supporting optimum ventilation control (OVC) or ventilation-on-demand (VOD) control decisions for cost saving without compromising safety and health.

\section{Delayed Hazard Mechanisms for EWS Applications}

The time delay between a cause and the mine system's response in hazardous concentration increase is the key element of EWS. Such a delayed process is shown in Fig. 1a for a methane concentration pulse traveling from location 1 to location 2 in an airway. The methane concentration at location 2 is expected to be lower than location 1 due to advectiondiffusion as the pulse travels with the air velocity and disperses. If the concentration at location 1 is not dangerous, likewise will be the concentration at location 2. However, if the traveling concentration front encounters a concentration build-up from another distributed source, it leads to gas accumulation that may cross the hazard threshold after a delay time, shown in Fig. 1b. A simple summation of the concentration values from two or three distributed sources can be performed to determine the concentration build-up at a downstream location. A computational model will not be required in this case. However, the reality in a mine is more difficult. There are numerous distributed sources with different airflow rates and velocities which may contribute to gas accumulation at a downstream location. The mixing equation becomes more complex than a simple summation and as such it is necessary 


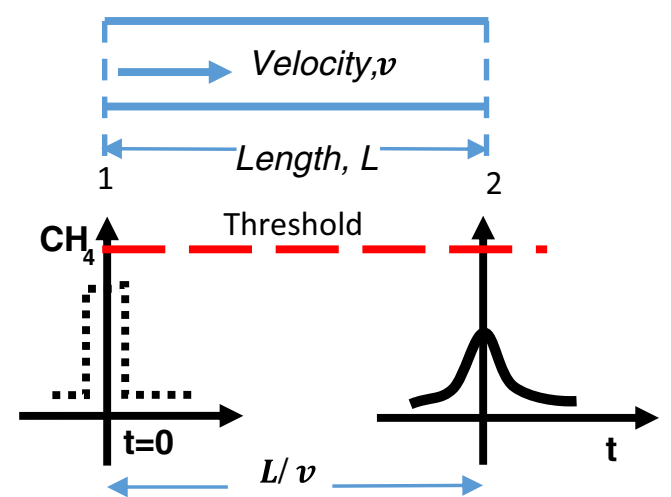

(a)

Travel delay time without hazard

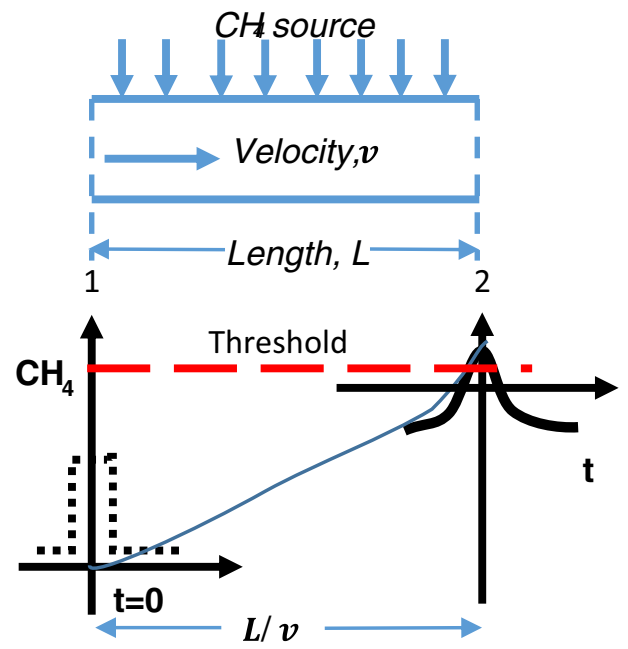

(b)

Travel delay time with gas accumulation hazard

Fig. 1 Methane concentration pulse with a travel delay time without hazard and $\mathbf{b}$ travel delay time with gas accumulation hazard

to use a numerical model capable of simulating the dynamic mass transport processes.

Another delayed mechanism is shown in Fig. 2 depicting methane inflow from the gob into the airway associated with a response delay as a result of pressure-driven methane liberation. Although no problem may be caused by methane release due to slow barometric pressure changes under normal weather conditions, sudden change may induce methane from the gob into the airway as demonstrated by numerical studies [4]; a summary of the results is shown in Fig. 2.

Gas concentrations in the mine airway always change and these changes are related to different disturbances. These changing concentration values might reach a threshold limit value at any location. A concentration value at a monitored location might not be critical but the changes which have caused a below-critical variation may simultaneously result in a threshold value crossing at a different location other than at the monitored location.
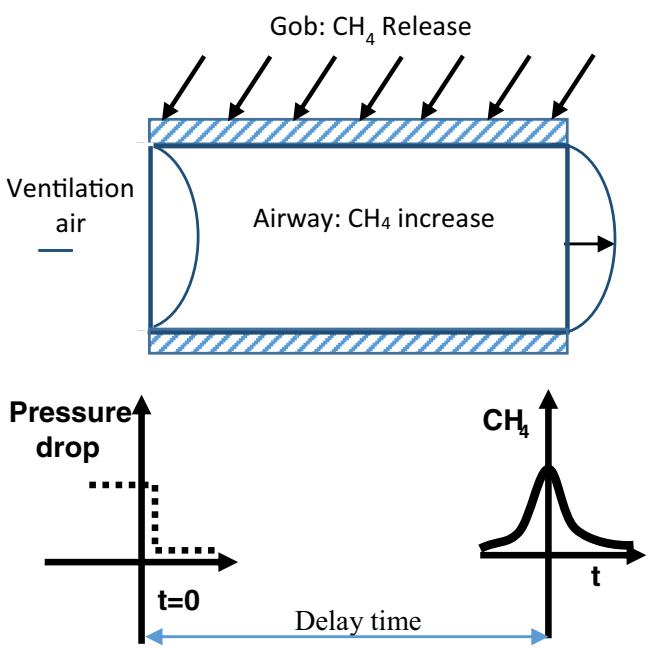

Fig. 2 Pressure drop induces methane inflow from gob into airway showing response delay

Threshold crossing may be due to the continuous downstream addition of concentration to the increasing level as a result of cascading. Changes which may trigger continuous increase of gas levels with a time delay may include sudden gas in-burst, roof collapse, fan malfunction, barometric pressure changes causing gob out-gassing, and mine fire. These cases must be modeled with a DMVM to determine how they affect the dynamic signature of gas concentrations in the mine airway.

\section{The Concept of the EWS}

The new and innovative components in the EWS are as follows:

a. Forecasting is made in time by the DMVM stemming from the AMS data in accelerated, simulation time scale to predict any likely event in the near future in real time that may compromise safety; and

b. Forecasting is made in space by the DMVM mine-wide, in order to evaluate safety at any critical working area, even at a place where no monitoring station is installed.

Figure 3 depicts the schematic layout of monitored and critical locations for the explanation of the "forecast in space" concept. The criteria used to determine a critical location is based on the areas that may have high concentration of gases that could lead to threshold crossing.

While all nodes are modeled, only a few are monitored; the critical location $(\mathrm{C}, \mathrm{m})$ may not have a monitor and a hazardous concentration may be "sensed" with a model prediction. This is an innovative element in the EWS system, improving the limitation in current monitoring systems. Note that a critical location may not be monitored at the mine but all locations will always be predicted by the DMVM. 
Fig. 3 Monitored (M), modeled $(\mathrm{m})$, and critical (C) locations at a mine

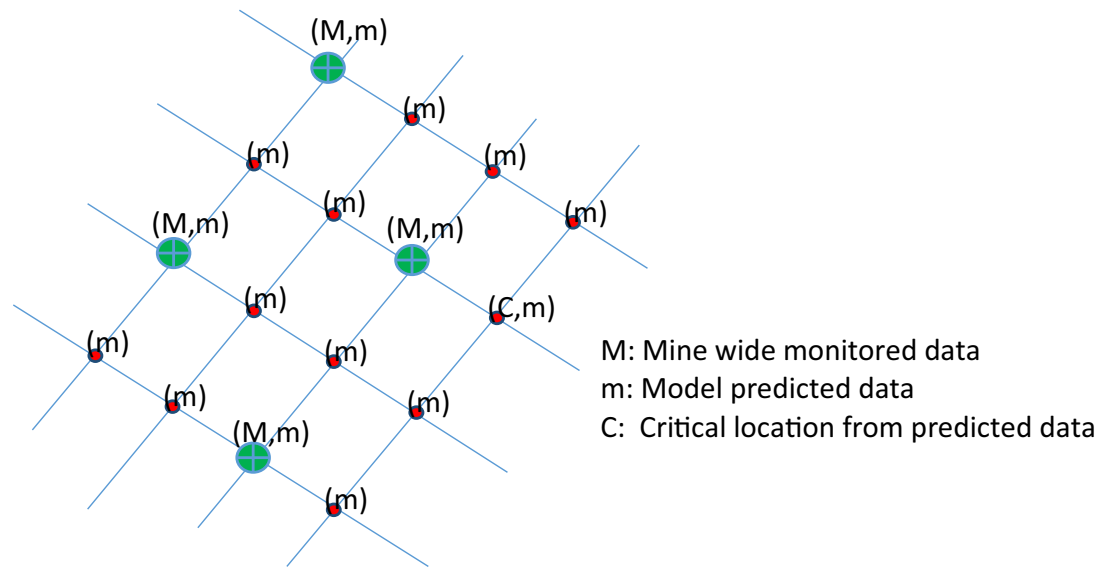

The schematic diagram for EWS evaluation for accident prevention is depicted in Fig. 4. The EWS runs five realtime processes simultaneously, shown in Fig. 4, performing:

a. Interpretation of the AMS signals in comparison with the DMVM real-time simulator (RTS); b. Validation and calibration of the DMVM model against the AMS sensor readings during long periods of regular mining operations;

c. Identification of unexpected, deviated, AMS signal patterns signifying the beginning of potentially hazard conditions;

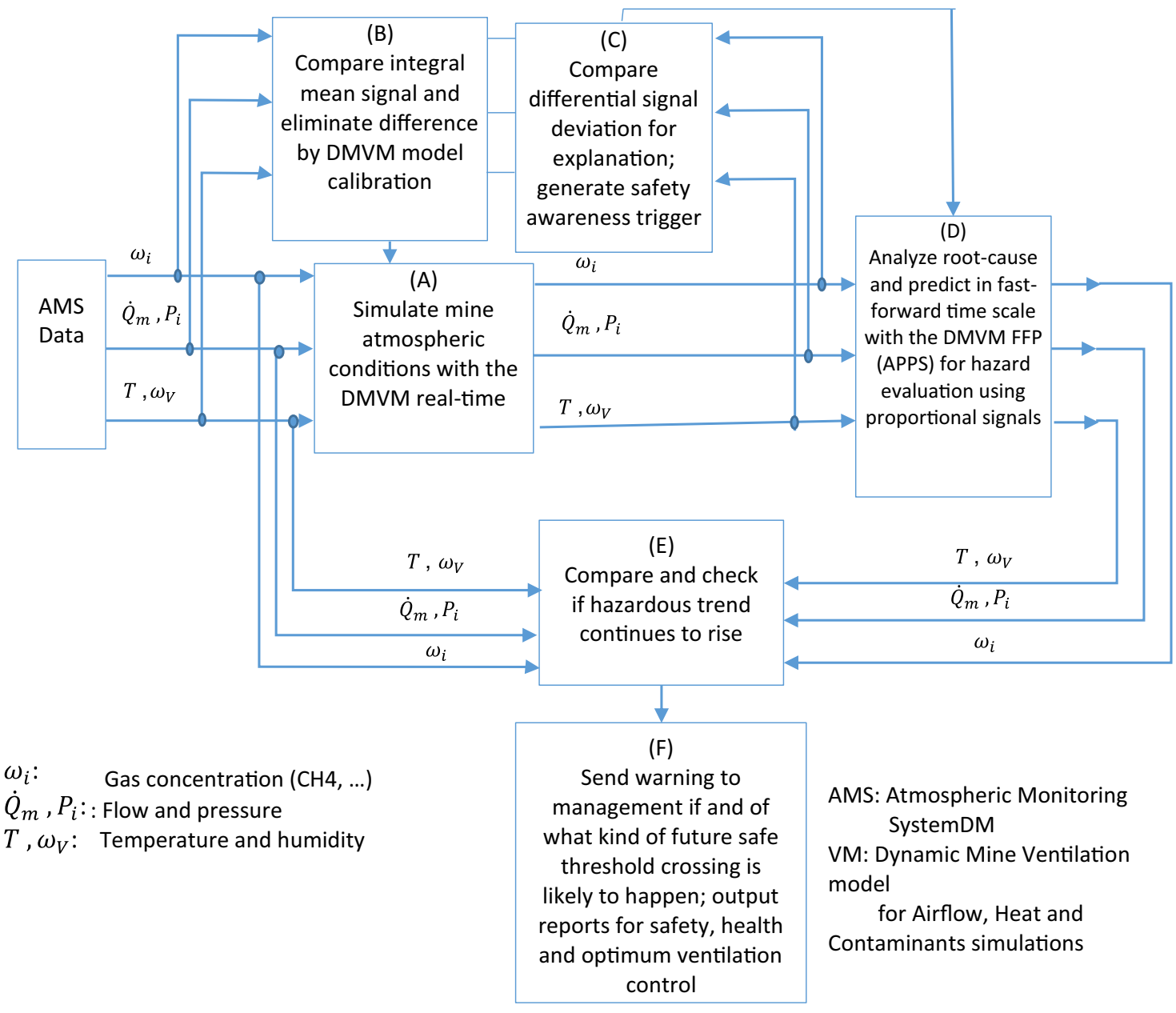

Fig. 4 Schematic diagram for sensors and EWS evaluation for accident prevention 
d. Identification of plausible reasons for unusual and excessive differences between the elevated AMS signals and DMVM model results other than caused by possible noise or sensor malfunction; and specification of them as root cause deviations in DMVM source terms and/or boundary conditions;

e. Forward prediction with the FFP for extrapolation of the trend with time until crossing the maximum threshold value occurs for evaluating the need for an EWS alarm;

f. Production of a warning EWS message (if any) or a status report to support OVC or VOD ventilation control.

The hazardous condition is checked and the accident scenario is evaluated during its evolution to display a warning for preventive measure before the "would be" accident happens in order to avoid it.

The air parameters and their changes are simulated by the DMVM model in fast forward prediction (FFP) mode calculating gas concentrations at critical (forecasted) locations and critical (forecasted) time in the near future. The FFP is a subset of the DMVM for fast-running, short-time applications (APPS). Since the simulation time is much shorter, by orders of magnitude than the change in mine's assumed signal at critical location in real-time, an advantage in time may be gained for warning message for accident prevention. The air parameters and the changes are "sensed" by the DMVM model all over the mine including places where there are no sensors.

Fig. 5b shows the concept of the EWS for a methane concentration example at an unmonitored location that may be a critical workplace that is different from the AMS location that triggered the hazard examination. The EWS works similarly to that in the previous case described in Fig. 5. The only difference is that the forward prediction is performed by the DMVM for the unmonitored location.

\section{Elements of the EWS}

The EWS is designed to be embedded into the infrastructure of a modern mine with a mine ventilation and control system. The main components necessary for EWS to function are a number of atmospheric sensors such as air parameter sensors for velocity, airflow rate, relative humidity, pressure and temperature, and gas concentration sensors in the order of at least a few dozen for a mine with a few hundred airways. Atmospheric sensors in strategic locations must be monitored real time. Roof stability and operating parameters in the mine should as well be recorded continuously.

The EWS requires real-time data to be passed from the mine monitoring system for evaluation and, if necessary, forward prediction. The innovative approach of the EWS is that it links together the mine ventilation model, the data stream from the real-time sensors, and an expert system with a forecasting evaluation program that provides a warning message, flagging imminent or near-future safety hazards.

The physical components of the EWS are defined by its functions as follows:

a. A mine-wide AMS connected to a central data processor, a DMVM for simulating ventilation and atmospheric air conditions in the mine, and a communication graphical user interface (GUI) to set up the EWS;

b. Calibrator of the DMVM RTS against the AMS data stream after low-pass, integrating filters;

c. Signal comparator to evaluate short-term differences between the DMVM RTS and the filtered AMS data and to trigger the EWS evaluation if needed;

d. Root cause analyzer for the explanation of the triggered event;

e. DMVM FFP (APPS) model element for analyzing the future outcomes of the triggered event;

f. Communication interface for EWS warning and status report for OVC or VOD.

The EWS is developed for use by operating mines which already have a mine ventilation model. All modern mines have advanced, monitoring, and mine information systems and adopted at least one or sometimes more ventilation models of their choice, e.g., VnetPC [30] or Ventsim [21]. It is assumed that any ventilation software can be converted to MULTIFLUX [25, 28] used for both the DMVM and FFP (APPS) components.

The DMVM components in the EWS may be conveniently configured through the GUI in Ventsim. The GUI may also be used to map the sensor system of the AMS and relate the locations to the layout of the mine airway system. LiveView provides the external connection of the data sources from the sensors and displayed them in the Ventsim GUI [21]. The GUI is an important tool for manual interactions and tests in Ventsim, but not needed nor sufficient for the automatic, continuous evaluation of the AMS data stream against the real-time simulation results of the DMVM in a continuously modeled mine.

The dynamic simulation modules in Ventsim, applied to contaminants, gases, diesel particulate matter (DPM), and heat provide time-dependent simulation results by tracking the changing ventilation conditions and contaminants throughout the mine at specific times [22]. However, the difference between the Ventsim LiveView with the dynamic simulation modules and the DMVM FFP (APPS) in the EWS is substantial as the EWS includes additional, new components:

- Calibration of ventilation, heat and gas models by integrating filtering. This part is essentially important to depress the natural variation of the signals due to 


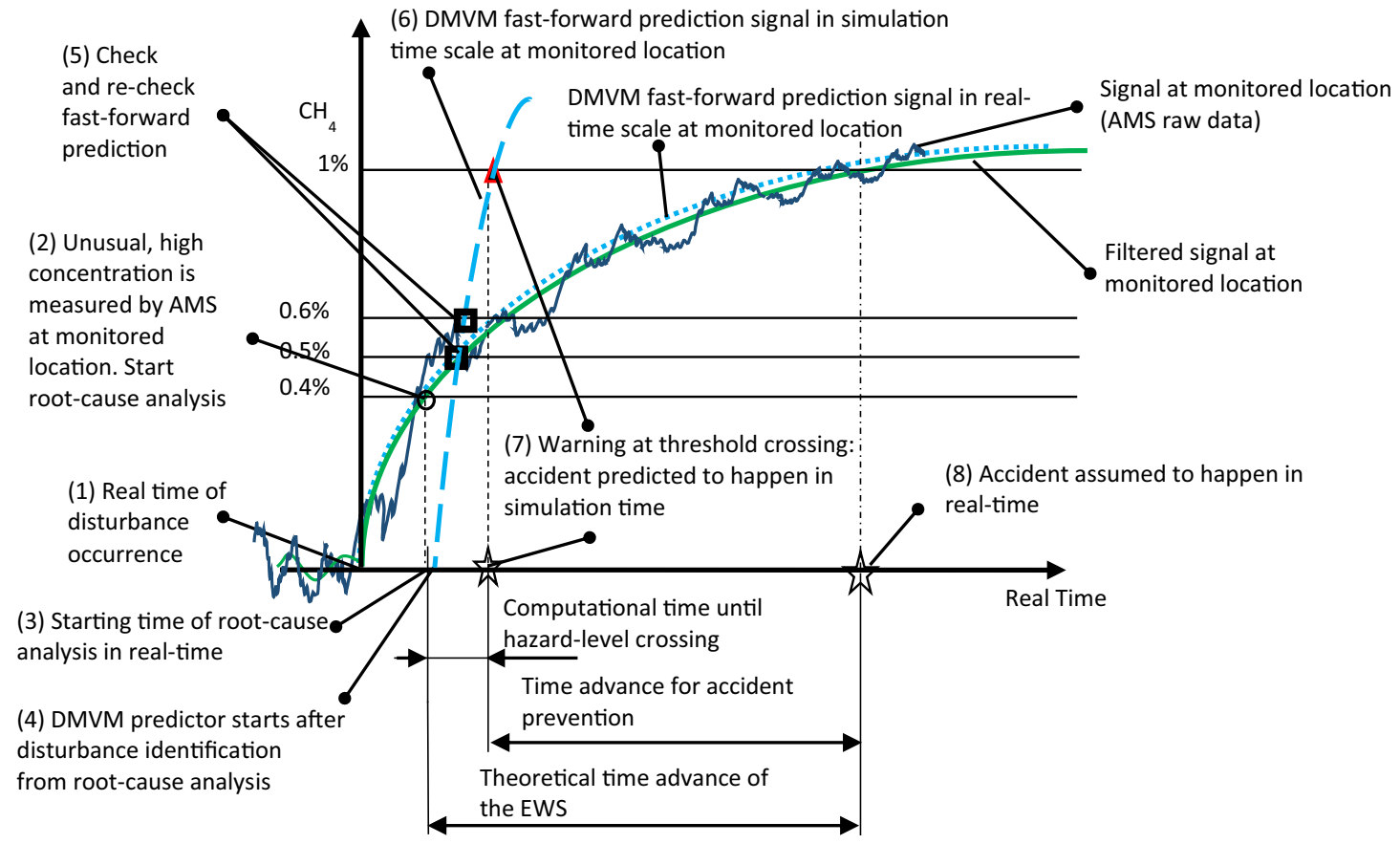

a

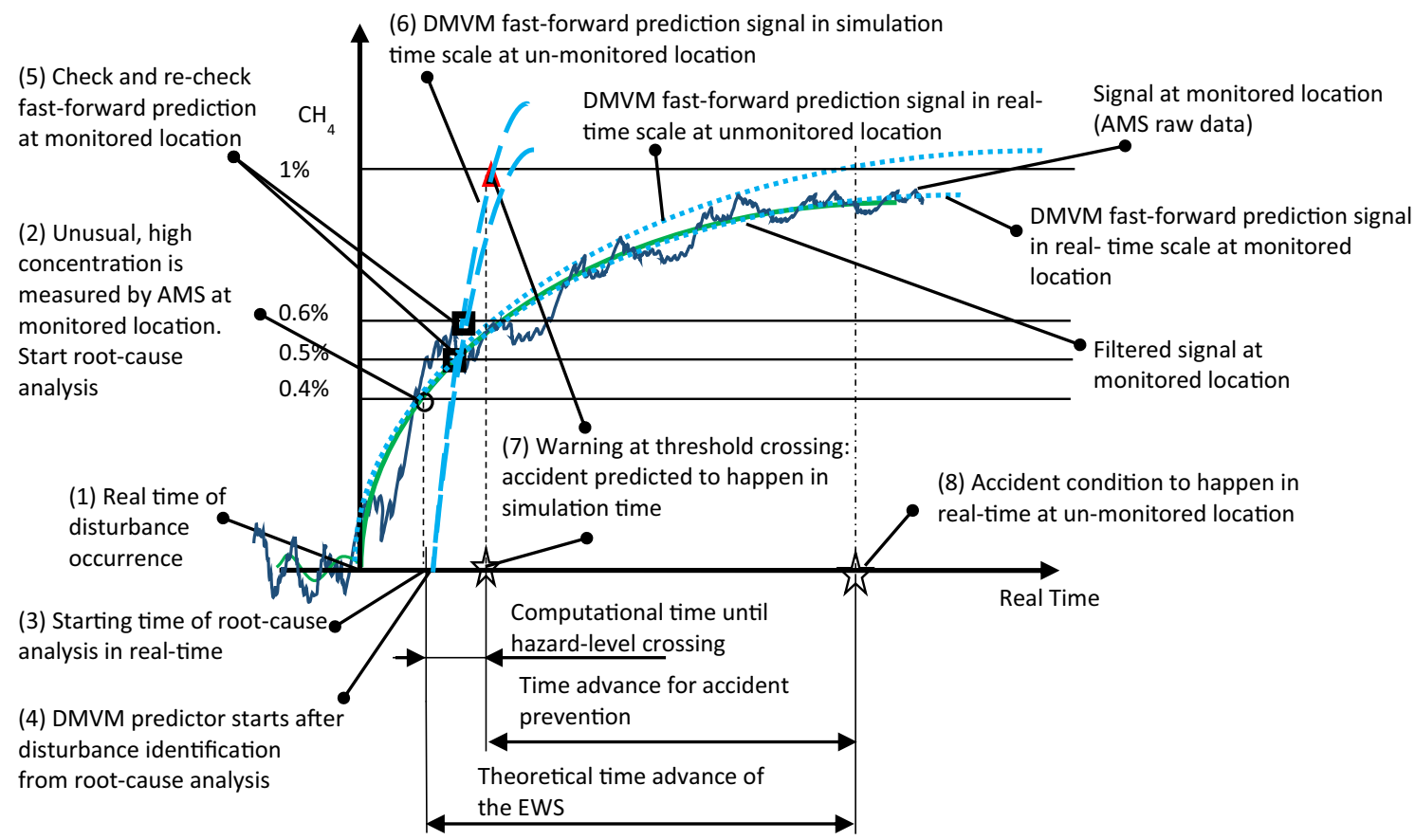

b

Fig. 5 Schematic diagram of a the FFP (APPS) "forecast in time" concept description using methane concentration at a monitored location and $\mathbf{b}$ the EWS "forecast in space and time" concept description using methane concentration at a critical location (unmonitored)

disturbances from mining operations and perhaps from changes in the intake parameters; as well as raw differences between model predictions and measured data. Comparison examples are shown in Appendix between modeled and measured data in an operating mine, justifying the need for automatic model calibration of the DMVM.

- Continuous monitoring of real-time signals and evaluating the difference as deviation between model and measurement. 
- Automatic, real-time, root cause analysis if the difference is found beyond tolerance level to determine and verify the likely cause of the observed difference.

- Forward prediction with the DMVM FFP (APPS) component for checking the likelihood of accident threshold crossing in the near future.

It is noteworthy that the DMVM with its capabilities in the EWS application is also a desirable software element in the OMV and VOD control systems.

Figure 6 is a block diagram showing the link between AMS data, the Ventsim, and the EWS software.

\section{Forward Prediction in the DMVM FFP}

The DMVM FFP (APPS) predicts all air parameters at all locations independently from the DMVM model element. The DMVM and the FFP (APPS) model element run on two different time scales. The two models share the same baseline Boundary Conditions (BC) and the airway flow and transport properties. The FFP (APPS) predictor model is controlled by a set of $\mathrm{BC}$ and source terms, representing the information of the changing conditions from normal operations. The baseline $\mathrm{BC}$ and source terms for normal mining operations are identified and tuned by the calibration of the DMVM (and allowed to change only by the automatic calibration slowly by integrating, low-pass filtering in weeks, days and perhaps even in shifts but not in hours). The BC and source terms in the triggered EWS evaluation by the DMVM FFP are deviated from those of the baseline values by the root cause analysis for the suspicious conditions, checked and corroborated against the mining operations, including mine production data (MDP), VOD control data if available, roof stability monitoring data (RSM), in addition to the AMS data.

Forward prediction algorithms are developed, using the FFP in predictor mode. Two methods are available: (1) fast, direct simulation with the DMVM and (2) an innovative, differential forward prediction algorithm based on the use of the Jacobian matrices between differential $\mathrm{BC}$ parameters and differential responses for air flows, concentrations of critical mine gas components, and heat. Direct simulation deals with the CED solution of the entire mine model [28] whereas the Jacobian model is a preprocessed, matrix-vector algorithm. The forward prediction time with the Jacobian model is short, requiring only matrix-vector multiplications. However, the direct simulation method is preferable due to the high computational efficiency of the MULTIFLUX solver engine. For example, the CPU solution time of a 27,000-branch mine flow network model is $1.6 \mathrm{~s}$ in a laptop computer with a single Intel i7 core [28].

Figure 6 is a block diagram showing the link between AMS data, Ventsim software, and EWS software.

\section{Testing the EWS and Flagging Safety Criticality Conditions at Critical Location}

Data from the sensors are collected at regular time intervals in real applications. In this study, emulated, synthetic data used in lieu of real sensor data for two reasons: first, accidents are rare and not expected, nor desired to occur during the tests of the EWS; and second, to be able to conduct the tests under controlled, known initial, and boundary conditions. The synthetic data are emulated using the native DMVM mine ventilation model that is assumed to be calibrated. Therefore, no systematic error is suspected in this study simplifying the need for the performance validation.

The test comprises of using the "blind" emulated sensor data; analyzing the trends of the signals for the root cause of the changes; and forward predict from that point the possible outcome of the perceived scenario. If threshold crossing for criticality is found from the DMVM FFP model element, the test is considered successful for hazard prediction. The critical elements for success are (a) the accuracy of recognizing the
Fig. 6 Block diagram for link between the AMS, Ventsim, and EWS

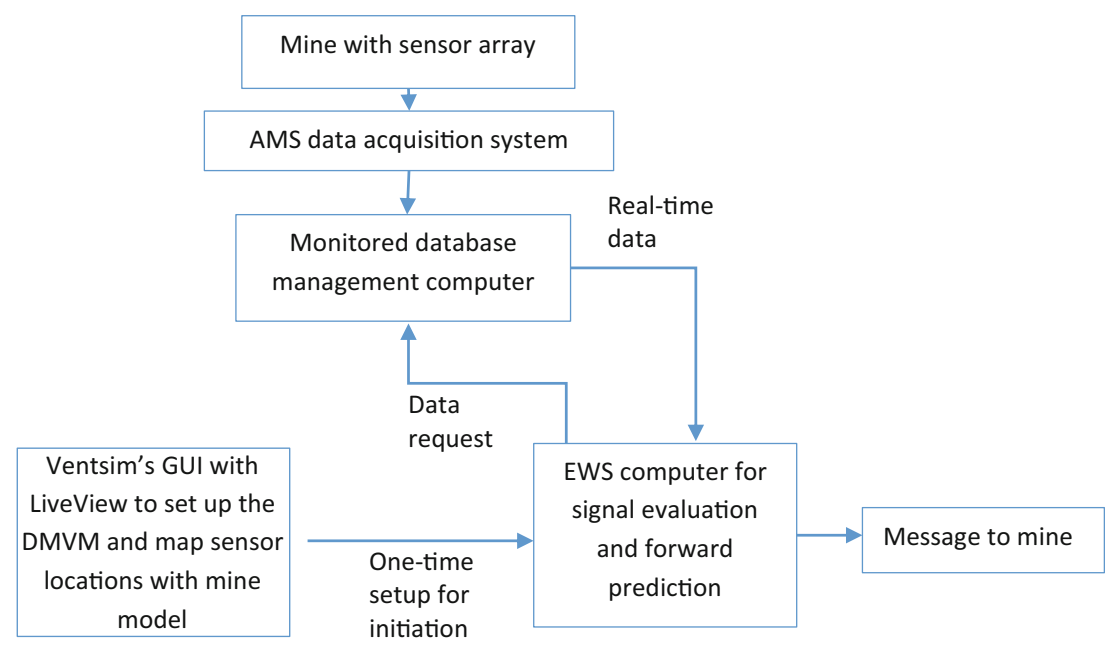


root cause of an unexpected signal change, crossing the tolerance limit of normal regime, and (b) the timely forward prediction, much faster than real-time of future outcome of the disturbance riding toward an accident in real time.

\section{Concept Demonstration by Modeling of Hazardous Scenarios}

The EWS system is tested by numerical simulations in its ability to identify hazardous atmospheric events in the ventilating air of the mine by comparing expected trends from a calibrated, dynamic ventilation model with those from monitored signals; and forecast hazardous scenarios during their evolution but before the thresholds for accidents are crossed for preventive interventions.

The atmospheric conditions in an operating mine regularly undergo significant but harmless variations which must be distinguished from those which may lead to accidents. To illustrate the challenge, examples are shown in Figs. 14 in through 18 in the Appendix for the range of expected variations in air velocity, temperature, barometric pressure, and relative humidity from mine measurements as well as from numerical simulation using two different ventilation models, MULTIFLUX and Ventsim. As shown, the confidence bound for signal variations may be quite wide and the numerical simulations, if not continuously calibrated as shown, may miss even the wide confidence bounds from the monitored signals [4].

\subsection{Description of Dynamic Model Calibration}

As part of the concept demonstrations, the necessity of dynamic model calibration is studied in an example. The DMVM model in MULTIFLUX is calibrated to match a time-dependent temperature simulation with variable air temperature measured in an operating mine. The goal of the simulation is to demonstrate the improvement in the agreement between monitored signals and the simulated result from the DMVM by model calibration that can be dynamically performed in real time over a sliding window of time-averaging. The simulation process uses hourly temperature values for a 32-day time period in the mine. The DMVM is set up for the vertical intake shaft in the mine, shown in Fig. 7. The DMVM includes dynamic, thermal-humidity model elements for advection, convection, and friction heat in the shaft; heat sources due to the intake fan and auto-compression in the $600 \mathrm{~m}$ deep intake shaft; and time-variable heat conduction in the rock strata around the airway.

\subsection{Description of Modeled, Hazardous Scenarios}

Typical scenarios are modeled and checked in forwardpredicting mode: (1) methane in-burst from encountering a pocket at the face; (2) airway blockage as a result of partial

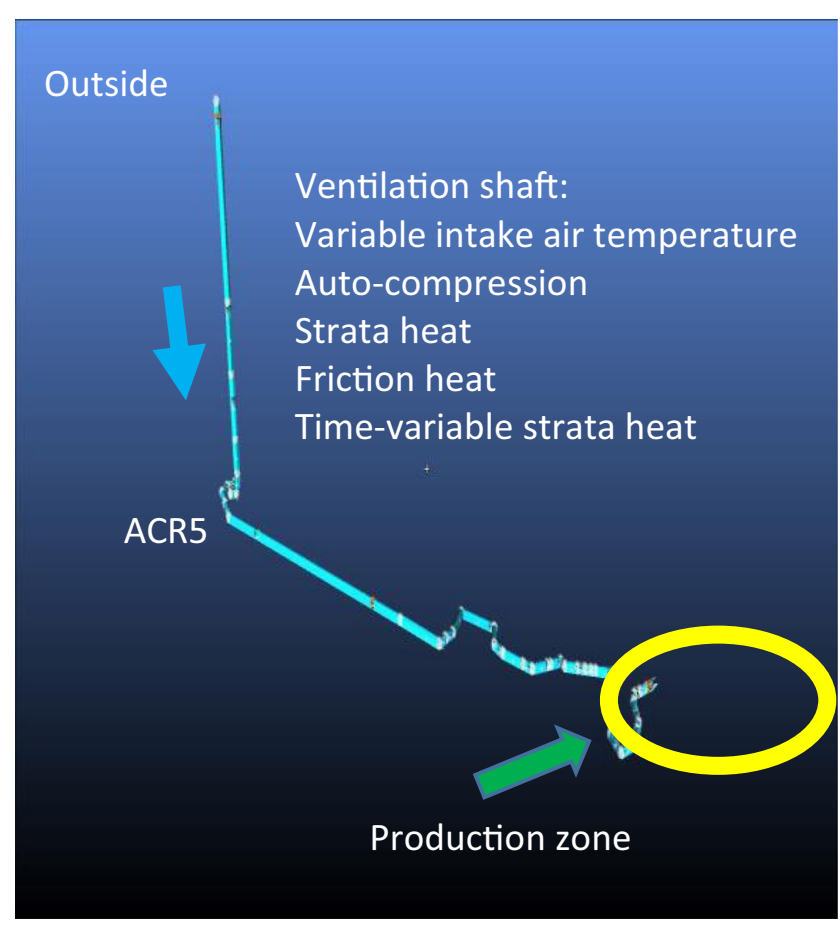

Fig. 7 The ventilation shaft in the DMVM model calibration example

collapse of a hazardous roof section in a mine; (3) atmospheric barometric pressure variations causing methane inflow from the gob; (4) booster fans malfunction and fan starts or stops causing barometric pressure variation that may trigger pressure unbalances and methane inflow from sealed areas, seams, or gob; and (5) fire heat load.

Table 1 summarizes the typical, modeled scenarios using two coal mine examples. The schematic layouts of mine 1 and mine 2 are depicted in Fig. 8 and Fig. 9, respectively. Eighteen selected, observed locations are marked in the models. These locations are represented in the models using markers called "dynamic monitors" in Ventsim. The observed locations include assumed monitoring sensor positions and critical locations (which are not necessarily monitored), determined by knowing the dangerous locations in the mine.

The modeling process is performed in two parts. First, the DMVM model is used and data are generated from it emulating sensors' output for a modeled malfunction situation. Second, the emulated sensor signals at some observed locations are used as assumed monitored data input to trigger the EWS system at $0.5 \%$ methane concentration. Since the signals are simulated, there is no need to start at $0.4 \%$ concentration as a first trigger level shown in Fig. 5a and b, nor is it necessary to re-check the signal trend at $0.6 \%$ concentration in the tests. Once the $0.5 \%$ methane concentration threshold limit value is crossed at any sensor, the EWS is triggered to start with a root cause analysis, followed by the forward prediction with the DMVM FFS at all locations. If the forward-predicted values lead to a threshold crossing of $1 \%$ methane for stopping work in a coal mine [1], an EWS alarm state is reached. 
Table 1 Modeled hazardous scenarios used in demonstrational examples

\begin{tabular}{llll}
\hline Case & Scenario & Hazard type & Mine layout example \\
\hline A & 1A (Base case for scenarios 2 and 3) & Methane in-burst (2 sources) & 1 \\
b & 1B & Methane in-burst (3 sources) & 1 \\
C & 1C (Base case for scenarios 4 and 5) & Methane in-burst (3 sources) & 2 \\
D & 2 & Airway blockage & 1 \\
E & 3 & Atmospheric barometric pressure variations & 1 \\
F & 4 & Fans malfunction & 2 \\
G & 5 & Fire heat load & 2 \\
\hline
\end{tabular}

The delay time is determined as the time required for the methane concentration to cross the threshold limit value of $1 \%$ for a particular critical location from the time the sensor triggers the EWS at $0.5 \%$ methane concentration. The delay time minus the computational time of the DMVM FFP is available as the advance time for preventive interventions. This approach is used in all five EWS concept demonstration examples. The DMVM FFP simulation takes approximately $2 \mathrm{~min}$ from the time a signal crosses the $0.5 \%$ methane threshold to the time of finishing the forward prediction reaching the $1 \%$ methane concentration threshold limit value. The simulation time of approximately $2 \mathrm{~min}$ has to be deducted from the delay time to determine the actual time gain for management to take action.

The time-dependent methane concentration results for each of the five scenarios are presented in three parts: (a) the native DMVM model simulation results, (b) the emulated sensor signals from the DMVM RTS used as monitored data input to trigger the EWS system, and (c) the DMVM FFP output signals.

The various cases modeled are described as follows with the corresponding methane sources given in Table 2. a. Two methane sources (scenario 1A, coal mine example 1) Gas in-burst is modeled by injecting only two methane sources: S2 the working face and S3 in the longwall return.

b. Three methane sources (scenario 1B, coal mine example 1)

Gas in-burst is modeled by injecting three methane sources: $\mathrm{S} 1$ at the upstream of the working face in addition to $\mathrm{S} 2$ and $\mathrm{S} 3$ with the same concentrations and flow rates as in scenario 1A. The same sensor locations are used.

c. Three methane sources (scenario 1C, coal mine example 2)

Gas in-burst into the mine airway is modeled by injecting three methane sources $\mathrm{S} 1, \mathrm{~S} 2$, and $\mathrm{S} 3$ in the same locations as in $1 \mathrm{~B}$.

d. Airway blockage as a result of partial collapse of a hazardous roof section in the mine (scenario 2, mine example 1)

This scenario is modeled by blocking one of the intake airways (branch 758) upstream of S2 and S3 sources, after 10 min into a 2-h simulation. Two methane gas sources S2 and $\mathrm{S} 3$ are modeled. In order to mimic an airway blockage, the resistance in branch 758, which is about $1066.8 \mathrm{~m}$ $(3500 \mathrm{ft})$ away from the longwall face is increased from 0.00170 to $8000 \mathrm{Ns}^{2} / \mathrm{m}^{8}$.

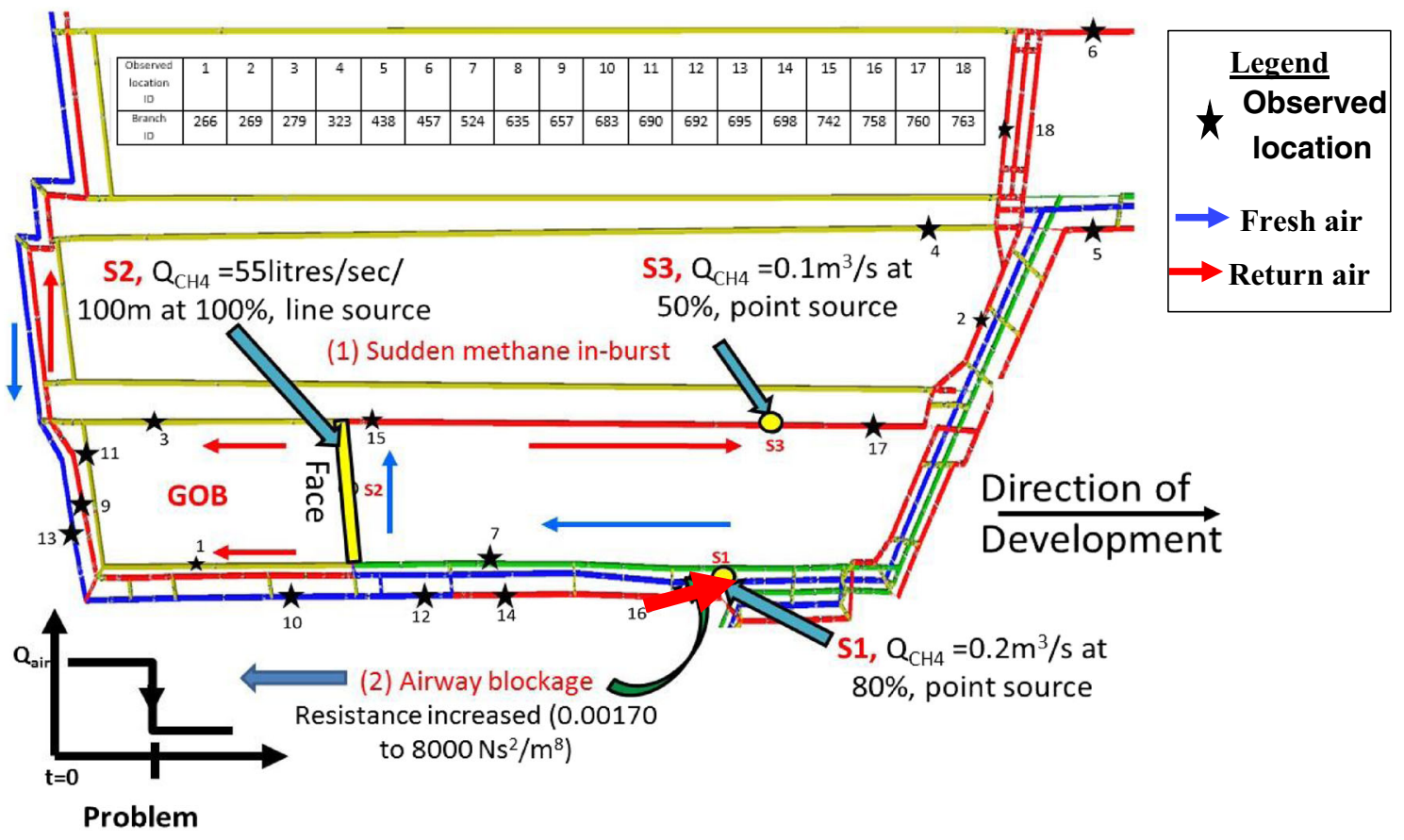

Fig. 8 Layout of coal mine example 1 with methane sources and monitored sensor locations in Ventsim 


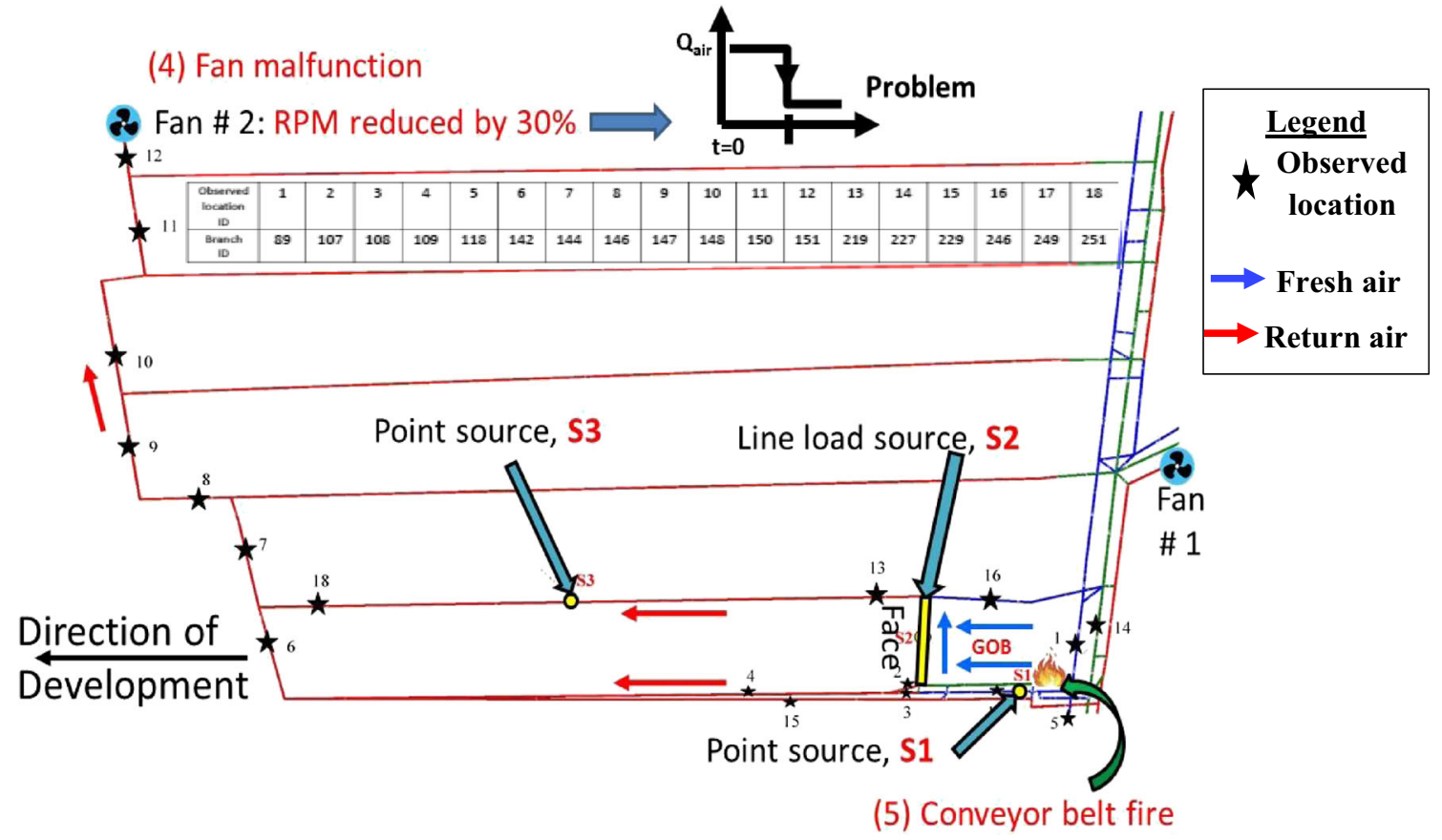

Fig. 9 Layout of coal mine example 2 with methane sources and monitored sensor locations in Ventsim

e. Atmospheric barometric pressure variations causing methane inflow from the gob (scenario 3 , mine example 1)

One methane gas source $\mathrm{S} 2$ is modeled in mine example 1. The effect of barometric pressure change upon methane inflow from the gob is modeled using the NTCF method [4] assuming a $2 \mathrm{kPa}(2000 \mathrm{~Pa})$ pressure drop relative to a previous, steady-state value of $100 \mathrm{kPa}$ in 20 min and keeping it low for an hour.

f. Fan malfunctioning (scenario 4, mine example 2)

A partial fan malfunction is modeled in mine example 2, by reducing one of the fans' static pressure by $30 \%$ (fan \#4 in branch 230) on the surface connected to the return shaft after 10 min into a 2-h simulation. All three methane sources, S1, S2, and S3 are kept unchanged.

g. Fire heat load (scenario 5, mine example 2)

Fire load is modeled using conveyor belt fire with $\mathrm{S} 1, \mathrm{~S} 2$, and S3 methane sources at the same locations as in mine example 2. A conveyor belt fire with an assumed burning rate of 1000 to $3000 \mathrm{~kg} / \mathrm{h}$ is modeled in branch 96 approximately $106.68 \mathrm{~m}$
(350 ft) away from the longwall face in order to examine its effect on gas concentrations and airflow parameters. The fire is set up to start from 600 to $3600 \mathrm{~s}$ during the simulation period of $2 \mathrm{~h}$.

\section{Results and Discussion}

\subsection{DMVM Model Calibration Demonstration}

First, the DMVM is set up from the geometry and input data for a mine example. Hourly, measured temperature data are used for the intake air as input to the DMVM model from a sensor at the surface, shown in Fig. 10a. The measured air temperature at the bottom of the shaft from another sensor, ACR5, is also shown in Fig. 10a, together with the simulated temperature output of the DMVM for the same location. As shown, the modeled and measured temperatures for the same location do not match well but running nearly parallel to each other with a $2.5^{\circ} \mathrm{C}$ shift between them. Model calibration is necessary for eliminating the effects of the unknown reasons. The amplitudes and slight phase lags relative to the outside, intake air temperature are nearly identical,

Table 2 Methane sources used for modeling

\begin{tabular}{|c|c|c|c|c|c|c|}
\hline $\begin{array}{l}\text { Source } \\
\text { ID }\end{array}$ & Source location & $\begin{array}{l}\text { Branch ID } \\
\text { Mine } 1\end{array}$ & $\begin{array}{l}\text { Branch ID } \\
\text { Mine } 2\end{array}$ & Source type & Concentration & Flow rate \\
\hline $\mathrm{S} 1$ & Long-wall intake & 758 & 249 & Point & $80 \% \mathrm{CH}_{4}$ & $0.2 \mathrm{~m}^{3} / \mathrm{s}$ \\
\hline $\mathrm{S} 2$ & Working face & 761 & 100 & Line load (across drift) & $100 \% \mathrm{CH}_{4}$ & $\begin{array}{l}55 \mathrm{l} / \mathrm{s} \text { in } \\
100 \mathrm{~m} \text { drift }\end{array}$ \\
\hline $\mathrm{S} 3$ & Long-wall return & 760 & 251 & Point & $50 \% \mathrm{CH}_{4}$ & $0.1 \mathrm{~m}^{3} / \mathrm{s}$ \\
\hline
\end{tabular}


Fig. 10 a Comparison of air temperature variations between measurement and un-calibrated DMVM simulation. b

Comparison of air temperature variations after DMVM calibration

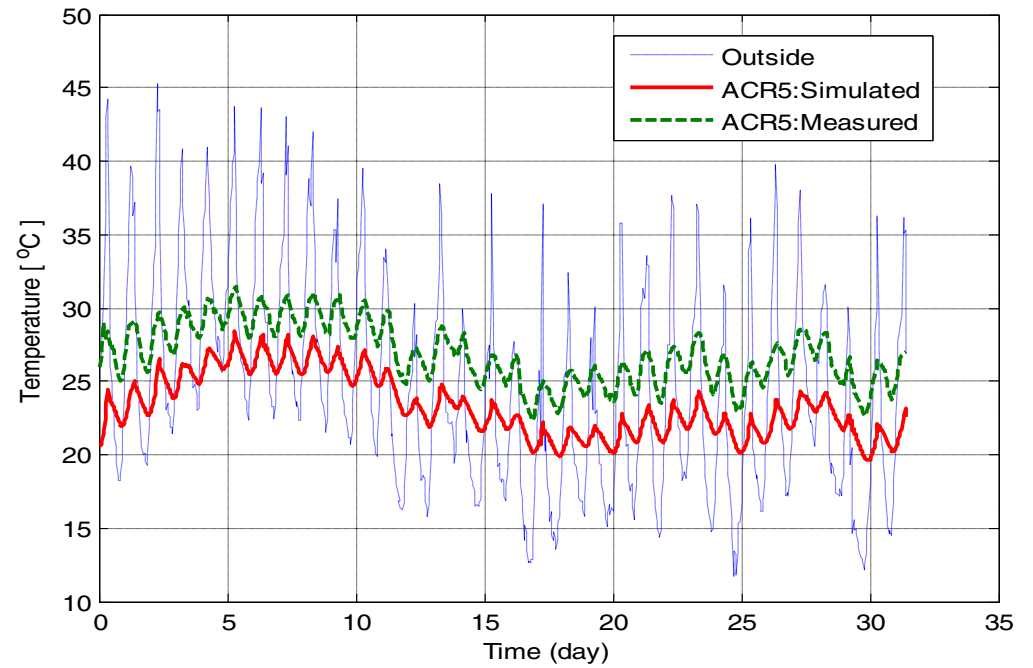

a) Comparisonof air temperature variations between measurement and un-calibrated DMVM simulation.

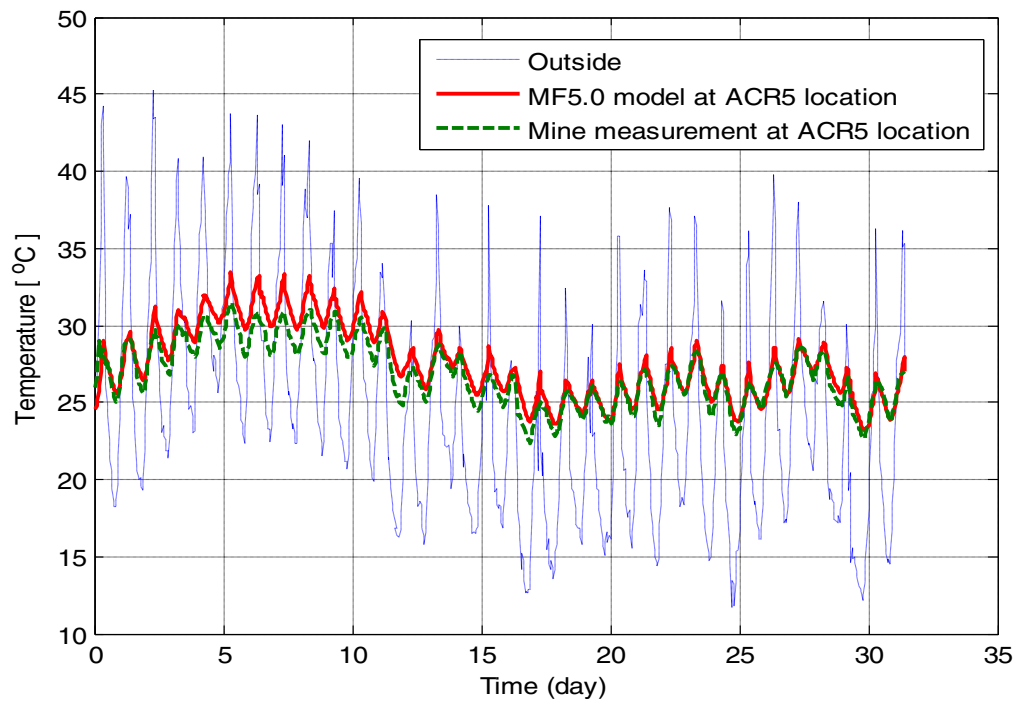

b) Comparisonof air temperature variations after DMVM calibration. confirming the proper choices for the thermophysical and geometric parameters in the model setup.

However, for eliminating the $2.5^{\circ} \mathrm{C}$ vertical shift, model calibration is necessary. The choice for calibration is the application of a line heat source in the DMVM model. The need for such a heat source is plausible as the variable virgin rock temperature distribution along the vertical shaft was not exactly known for correctly setting up the model without calibration in the example. The trial-and-error source calibration (that can be automated in the EWS) of a few hundred W/m heat source elevates the temperature variation at the end of the shaft to match the monitored temperature variation, shown in Fig. $10 \mathrm{~b}$.

Although beyond the present scope, higher order methods may be considered for model calibration using integrating filtering to depress unknown biases and disturbances from mining operations and from the natural variation of the intake parameters.

\subsection{EWS Forecast Concept Demonstrations for Intervention Assistance}

The time-dependent DMVM simulation results are shown only for selected locations where significant changes in methane concentration are obtained. The DMVM FFP results for methane concentration for scenario 1B are depicted in Fig. 11. The emulated sensor signals used as monitored data input to trigger the EWS system is shown in Fig. 12. This approach is used for all scenarios modeled in mine example 1 and mine example 2. However, only scenario 1B is demonstrated for brevity in Figs. 11 and 12.

Figure 13 depicts the DMVM FFP results for observed locations 15 and 17 triggered by the $0.5 \%$ methane concentration crossing at the location of sensor 15.

The results for scenario 1B show increased methane concentrations in branch 760 , which is a return airway downstream of 


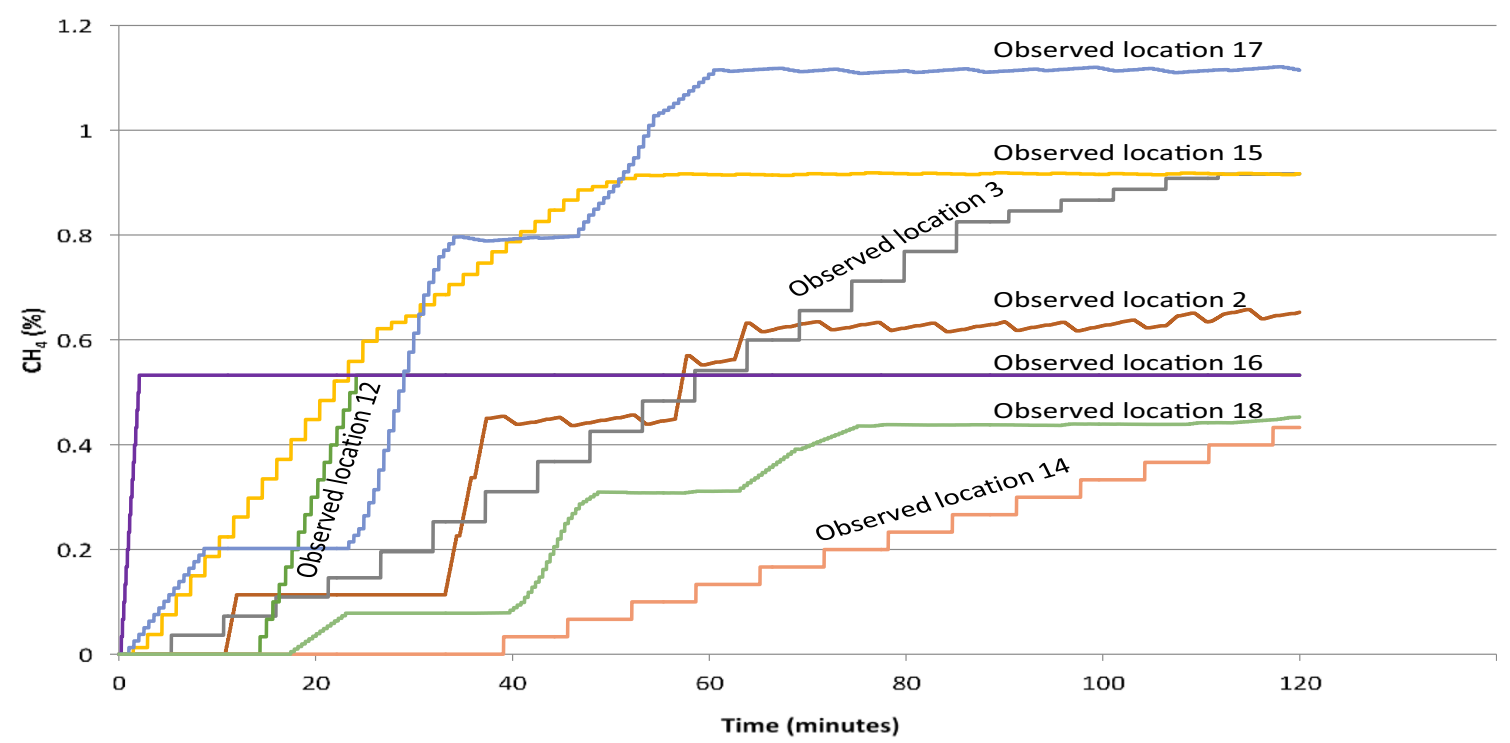

Fig. 11 Results of methane concentration at selected observed locations from native DMVM simulation in scenario 1B. Selected locations with significant changes only are plotted

the methane sources. Sensor 17 crosses the threshold and reaches a maximum concentration of $1.12 \%$ compared with that of a peak at $0.8 \%$ in the previous scenario $1 \mathrm{~A}$ where only two methane sources are used. This indicates that there is a possibility of threshold crossing from unknown methane source accumulation as the air flows downstream. A threshold limit value of $1 \%$ methane for stopping work is used in this analysis. The air parameters (airflow, velocity, and absolute pressure) are unaffected by the increase in methane sources.

The delay time in methane front arrival can be estimated as the time difference between the start of the forward prediction triggered by monitoring sensor 15 in branch 742 (which is a sensor at a location just at the end of the active face) and the threshold crossing time at $1 \%$ as a reference. Branch 742 crosses $0.5 \%$ in 21 min from the start of the methane in-burst, and branch 760 reaches $1 \%$ in $52 \mathrm{~min}$ as illustrated in Fig. 13a. Therefore, the delay time after awareness and before branch 760 crosses the threshold is $31 \mathrm{~min}$ (52 min minus $21 \mathrm{~min}$ ). The useful delay time must be lowered by the $2 \mathrm{~min}$ of forward prediction time to see the $1 \%$ threshold crossing in the simulation time scale, giving $29 \mathrm{~min}$ in the real time scale for preventive interventions after the EWS alarm is issued.

Scenario 1 shows that gas accumulation can result in a predictable delay time to evaluate and to be used for preventive interventions. Similarly, methane in-burst at the face that

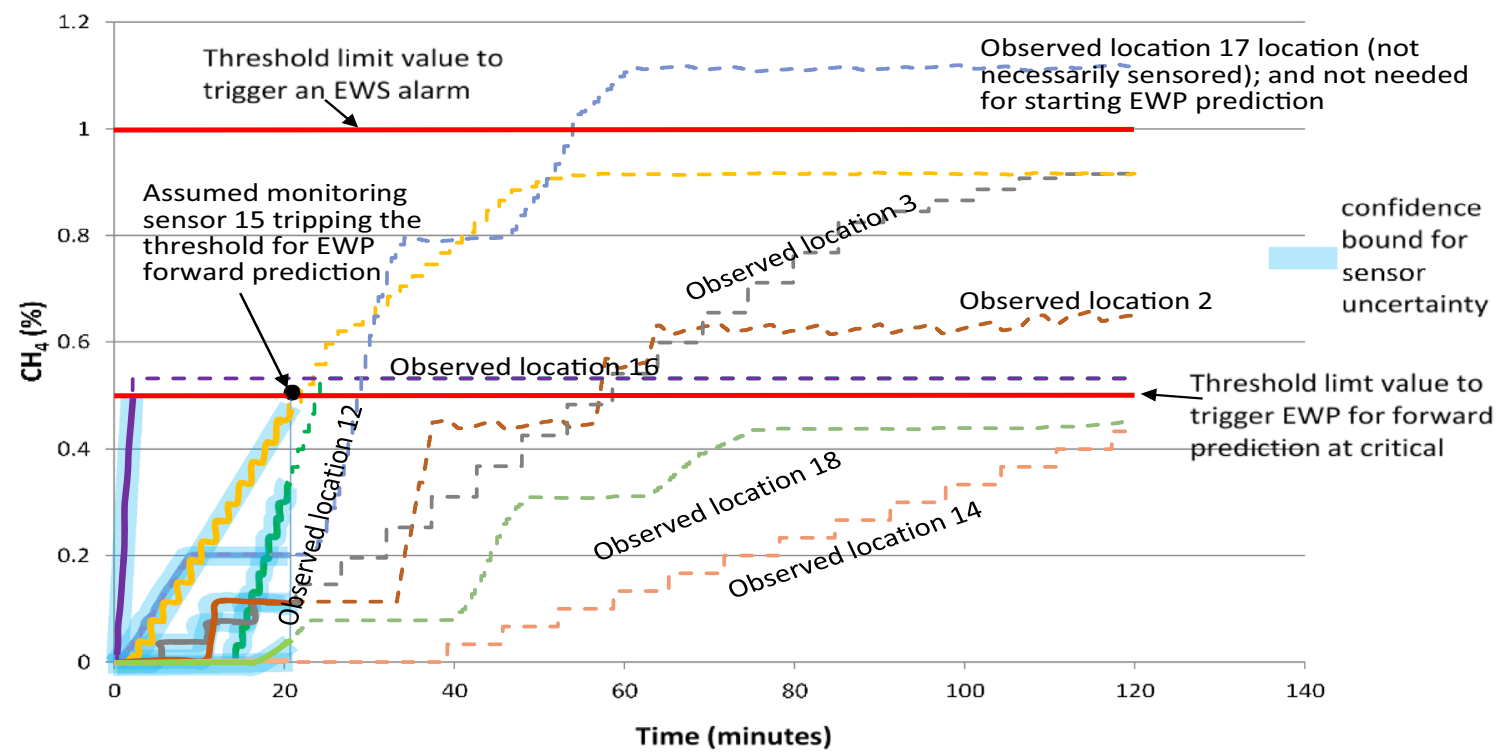

Fig. 12 Emulated $\mathrm{CH}_{4}$ concentration sensor signals used as assumed monitored data input to trigger the EWS system in scenario 1B (shown in thick lines with confidence bounds). Assumed sensors 15, 12, 16 (and 17 if installed) trip threshold for EWS forward prediction 

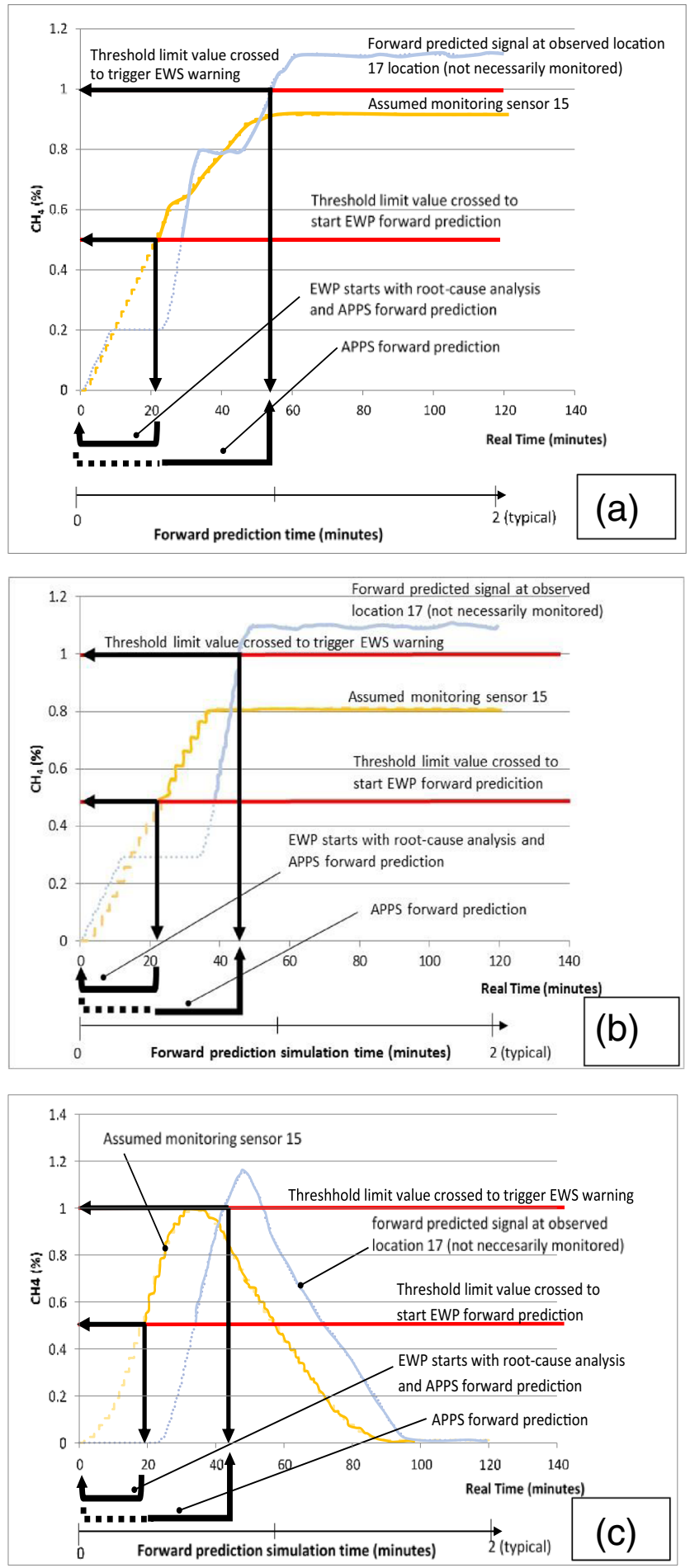

Fig. 13 FFP model forward prediction at selected observed locations in real-time and in fast simulation time scales for a scenario $1 \mathrm{~B}, \mathbf{b}$ scenario 2 , and $\mathbf{c}$ scenario 3 in mine example 1. Only two selected locations are shown

may be below-critical can also reach criticality for threshold crossing downstream with a well-predictable delay time.

Similar calculations are made for scenarios 1A, 2, and 3, shown in Fig. 11b and c, respectively. The forward predicted signal for location 17 in branch 760 is used again in scenarios
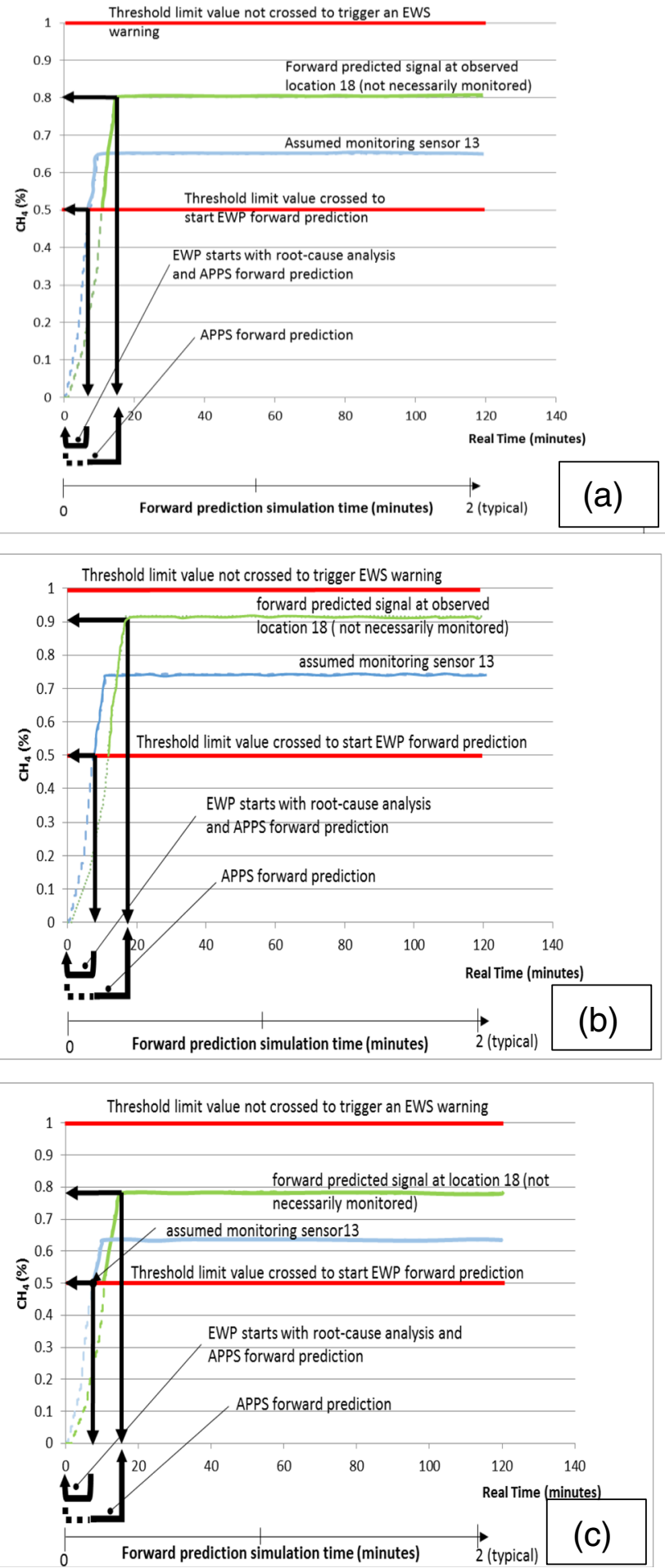

Fig. 14 FFP model forward prediction at selected observed locations in real-time and in fast simulation time scales for a scenario $1 \mathrm{C}$, b scenario 4 , and $\mathbf{c}$ scenario 5 in mine example 2 . Only two selected locations are shown

2 and 3 for EWS warning message evaluation, whereas the AMS signal from sensor 15 is used to trigger the EWS evaluation.

The result for scenario 2 in Fig. 13b shows that methane concentration increases to $1.1 \%$ from $0.8 \%$. This is due to the 
Table 3 Detailed results from the forward prediction for maximum concentration as well as the delay time in methane front arrival for all scenarios

\begin{tabular}{lllllll}
\hline Scenario & $\begin{array}{l}\mathrm{T} 1 \\
(\mathrm{~min})\end{array}$ & $\begin{array}{l}\mathrm{T} 2 \\
(\mathrm{~min})\end{array}$ & $\begin{array}{l}\text { Max. } \mathrm{CH}_{4} \\
(\%)\end{array}$ & $\begin{array}{l}\mathrm{T} 3 \\
(\mathrm{~min})\end{array}$ & $\begin{array}{l}\mathrm{T} 4=\mathrm{T} 3- \\
\mathrm{T} 1 \\
(\mathrm{~min})\end{array}$ & $\begin{array}{l}\mathrm{T} 5=\mathrm{T} 4- \\
\mathrm{T} 2 \\
(\mathrm{~min})\end{array}$ \\
\hline $1 \mathrm{~A}$ & 21 & 2 & 0.80 & $33^{*}$ & $12^{*}$ & $10^{*}$ \\
$1 \mathrm{~B}$ & 21 & 2 & 1.12 & 52 & 31 & 29 \\
$1 \mathrm{C}$ & 7 & 2 & 0.80 & $17^{*}$ & $10^{*}$ & $8^{*}$ \\
2 & 23 & 2 & 1.10 & 46 & 23 & 21 \\
3 & 19 & 2 & 1.18 & 42 & 23 & 21 \\
4 & 9 & 2 & 0.91 & $19^{*}$ & $10^{*}$ & $8^{*}$ \\
$5^{\circ}$ & 8 & 2 & 0.78 & $17^{\circ}$ & $9^{\circ}$ & $7^{\circ}$ \\
\hline
\end{tabular}

* No alarm is triggered since methane concentration is less than $1 \%$ and therefore, immediate action is not needed.

No alarm is triggered in terms of methane concentration increase; however, action must be taken as soon as a signal indicates the occurrence of fire in the mine and it is confirmed.

reduction in airflow as a result of the airway blockage. The airway blockage signals are assumed as step changes. The shape of the signal trends may be used in order to identify airway blockage as a root cause. The future effect of reduced airflow in scenario 2 is methane concentration increase that can be counteracted by dilution. A gas accumulation model, in the form of a fast-running FFP, is an adequate method for this example.

The result for scenario 3 in Fig. 13c shows that methane concentration increases to $1.18 \%$ from $0.8 \%$. The type of methane increase shows a dynamic, delayed signal trend. The process is too complex to be described by a simple FFP model. Therefore, an NTCF predictive model as a dynamic Jacobian gob model is used $[4,19]$ to simulate such a scenario.

Similarly, all the scenarios modeled in mine example 2 (scenarios 1C, 4, and 5) use this approach. The DMVM FFP model results are depicted in Fig. 14a, b, and c showing the forward predicted signal for location 18 for scenarios 1C, 4, and 5 , respectively. The results for scenario 4 , shown in Fig. 14b, indicate that a delayed mixing process has decreased dilution and increased methane concentration to $0.91 \%$ compared with that of the base case of scenario $1 \mathrm{C}$ with $0.8 \%$ value. However, no signal crossing with the $1 \%$ concentration threshold level is predicted.

No significant methane concentration change is seen from the face due to fire at a different location, shown in Fig. 14c. However, immediate action must be taken as soon as a signal indicates the occurrence of fire in the mine and it is confirmed. There is no need for further forward prediction for the other gas concentrations since the mine is placed in an alarm state in a real mine fire.

The detailed results are summarized in Table 3 for maximum concentrations as well as the delay time in methane front arrival from the forward prediction for all the scenarios based on the concentration values at sensors' locations (i.e., 15 and 17 for mine example 1; and 13 and 18 for mine example 2).

$T 1$, threshold value $(0.5 \%)$ crossing (Hazard Detection time) to trigger EWS forward Prediction; T2, forward prediction simulation time; $\operatorname{Max}$. $\mathrm{CH}_{4}$, maximum $\mathrm{CH}_{4}$ concentration from forward prediction; $T 3$, safety threshold value $(1 \%)$ crossing time to trigger EWS alarm; T4, delay time required for $\mathrm{CH}_{4}$ concentration to cross the threshold limit value of $1 \%$; $T 5$, actual gain time for management to take action.

\section{Conclusions}

- The results show that concentration of methane in the airway might be less than the threshold limit value at monitored locations but it may reach critical concentration at un-monitored locations downstream, detect-able by the DMVM.

- A fast-running DMVM FFP in the EWS can forward predict the concentration values downstream of monitored locations everywhere before hazardous changes may cause critical threshold crossing, giving advance time for preventive interventions to avoid the accident from happening.

- The EWS concept is tested against typical, simulated signals for potential hazard scenarios under controlled conditions. Significant time gain, in the order of $20 \mathrm{~min}$, is seen in the examples between the hazard detection time and the critical threshold crossing time at critical locations.

- If credible, it is prudent to use the EWS warning for preventive interventions and not to wait for the safety threshold crossing when the mine has to stop operation or evacuate miners at the instant of violating the safety limit value for critical gas concentrations.

- The functionality and credibility of the EWS must be tested in computer simulation as safety violation scenarios in an operating mine are very rare and testing the EWS under such scenarios is impractical and retroactive.

- Monitoring sensors which sound alarm at a lowered threshold value can be used for preventive interventions only if the EWS is operated in real-time cooperation for signal evaluation enhancement with a fast-running DMVM FFP for forward prediction to exclude frequent false alarms.

- To offset the cost of the software and hardware involved in the EWS, it is prudent to use its "deep learning" capabilities for evaluating the conditions for OVC and VOD control. For example, the DMVM provides output values for safety factors for health and safety conditions from which the conditions of over-ventilation can be readily evaluated. 
Acknowledgments A research grant from National Institute of Occupational Safety and Health (NIOSH), USA, is gratefully recognized for the MULTIFLUX model tests in the "Assessing, Modeling, and Cooling Underground Workings in Deep and Hot Mines" project.

The research was thankfully supported by the GINOP-2.3.2-15-201600010 in the "Development of enhanced engineering methods with the aim at utilization of subterranean energy resources" project of the Research Institute of Applied Earth Sciences of the University of Miskolc in the framework of the Széchenyi 2020 Plan, funded by the European Union, co-financed by the European Structural and Investment Funds.

Funding Information The proof-of-concept study in the "Early Warning Safety Hazard Predictor for Preventive Ventilation" project was thankfully sponsored by the Alpha Foundation for the Improvement of Mine Safety and Health, Inc. (ALPHA FOUNDATION).

\section{Compliance with Ethical Standards}

Conflict of Interest On behalf of all authors, the corresponding author states that there is no conflict of interest.

Disclaimer The views, opinions, and recommendations expressed herein are solely those of the authors and do not imply any endorsement by the ALPHA FOUNDATION, its Directors and staff.

\section{Appendix}

\section{Uncertainty Range as Confidence Bound of Monitored Signals in an Operating Mine}

Agreement and measurement uncertainty in an operating mine are evaluated between monitored signals and mine ventilation model results from MULTIFLUX and Ventsim. Measurement data at 57 locations are collected in an operating mine over a period a few days.

Figure 15 shows the comparison between the confidence bound for measured velocities and the results from the
MULTIFLUX and Ventsim models. The confidence bound for velocity measurement is $\pm 2.2 \mathrm{~m} / \mathrm{s}$. As shown, the uncertainty in the air velocity is quite wide, due to variations with the drilling and blasting mining operations and rubber-tired haulage. Since the air flow rate is a primary variable affecting concentrations, temperatures, and humidity distributions in the mine, it essential to include the fan control signals and some mine production data in the $\mathrm{BC}$ and source terms in the DMVM used in the EWS.

Figure 16 shows the comparison between and the temperature results from the models of MULTIFLUX, Ventsim, and the confidence bound, representing the variation of data over several measurements. The wetness factor was set to 0.2 and 0.05 in Ventsim and MULTIFLUX, respectively, for achieving best match between measured and modeled results. The confidence bound for temperature measurement is evaluated as $\pm 2.5^{\circ} \mathrm{C}$ from the scatter of the repeated measurements taken at different times during the day of the working shift. The high uncertainty in temperatures is due (a) to the crosseffects from the velocity uncertainties as well as (b) to the lack of the input temperature variation data in the $\mathrm{BC}$ of the MULTIFLUX and Ventsim models in the example. Note that the input temperature in the $\mathrm{BC}$ of the simulation models was set to constant value during the modeled time period.

Figure 17 shows the comparison between the confidence bound for barometric pressure from measurements and from the MULTIFLUX model at measurement locations. The confidence bound for the barometric pressure is $\pm 342 \mathrm{~Pa}$ from measurement observation. Note that the outside barometric pressure was set to a constant value.

Figure 18 shows the comparison between confidence bound for measured humidities and the results from the MULTIFLUX and Ventsim models. The confidence bound for relative humidity measurement is $\pm 15 \%$.
Fig. 15 Comparison between confidence bound for measured velocities and the results from the MULTIFLUX and Ventsim [4]

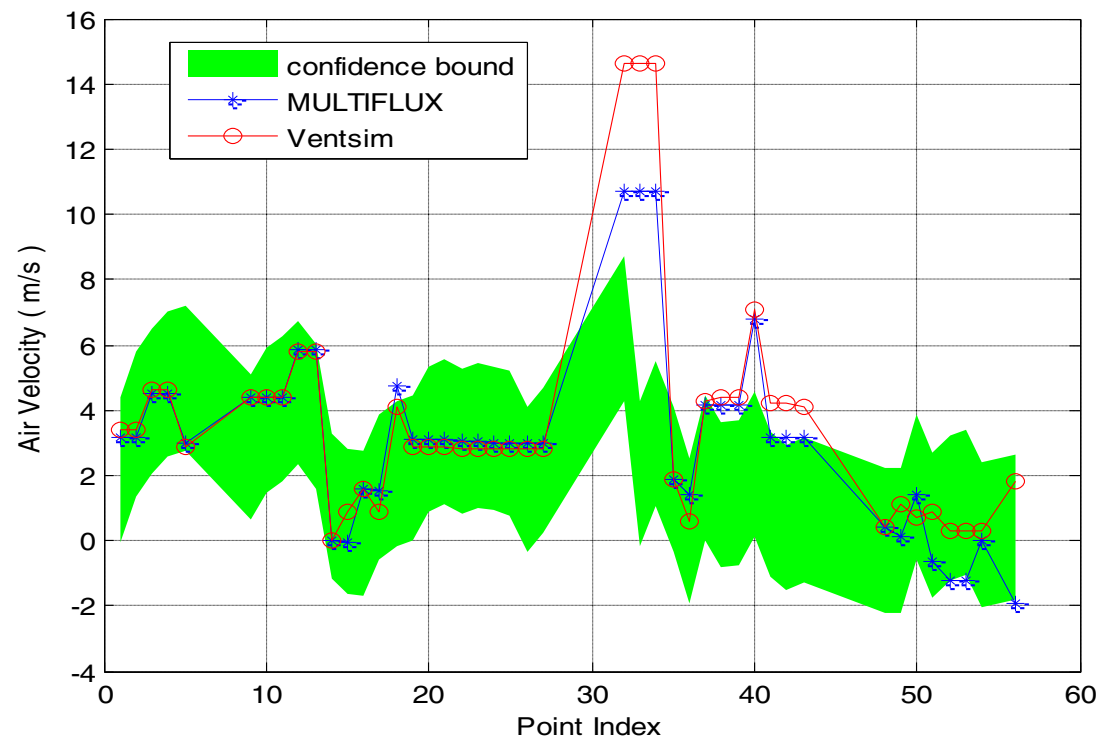


Fig. 16 Comparison between confidence bound for measured temperatures and the results from the MULTIFLUX and Ventsim [4]

Fig. 17 Comparison between the confidence bound for barometric pressure from measurements and from MULTIFLUX model at measurement locations [4]
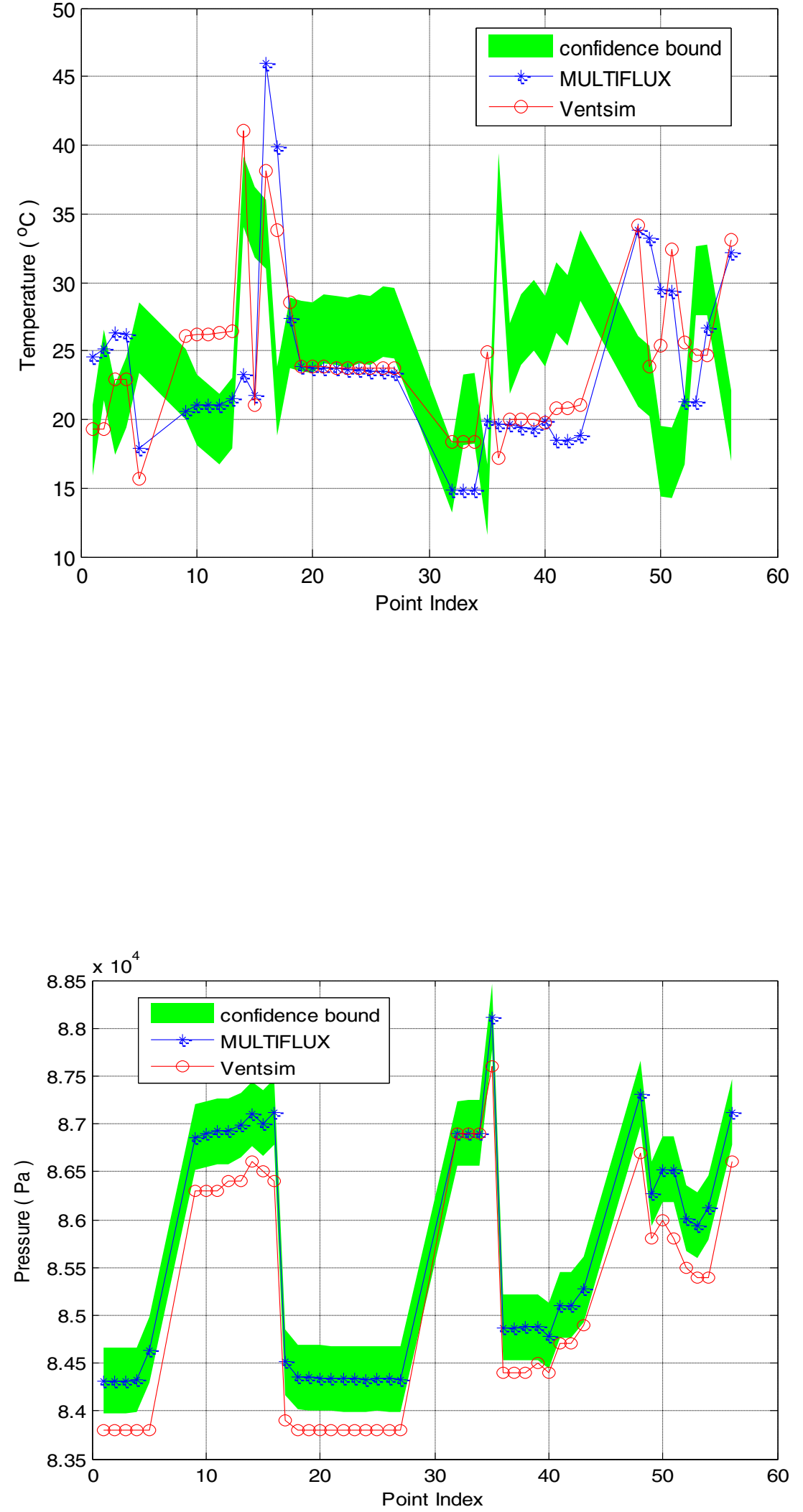
Fig. 18 Comparison between confidence bound for measured relative humidities and the results from MULTIFLUX and Ventsim [4]

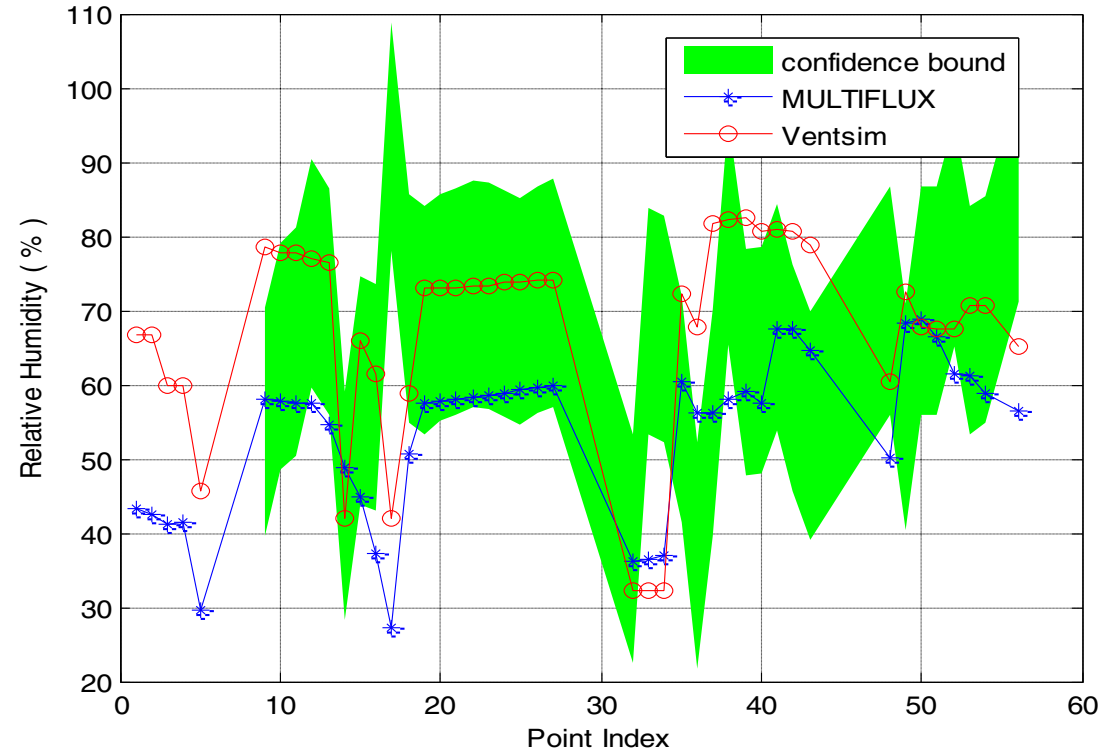

Open Access This article is distributed under the terms of the Creative Commons Attribution 4.0 International License (http:// creativecommons.org/licenses/by/4.0/), which permits unrestricted use, distribution, and reproduction in any medium, provided you give appropriate credit to the original author(s) and the source, provide a link to the Creative Commons license, and indicate if changes were made.

\section{References}

1. Code of Federal Regulations, 30 CFR part 75.323 (1996), Actions for excessive methane. http://www.msha.gov/REGS/FEDREG/ FINAL/1996FINL/5453(4).htm

2. Alpha Foundation Project (2016) "Early-Warning Safety Hazard Predictor for Preventive Ventilation" Final Report, Grant Number AFSTI14-03. https://www.alpha-foundation.org

3. Cheung, W.F., Lin, T.H., and Lin, Y.C., (2018). "A real-time construction safety monitoring system for hazardous gas integrating wireless sensor network and building information modeling technologies," Sensors, 2018, 18, 436, https://doi.org/10.3390/ s18020436. http://www.mdpi.com/journal/sensors, p. 1-24

4. Danko G, Bahrami D (2014) Contaminant species modeling with advection, dispersion, and stratification in ventilation networks. In: 10th international mine ventilation congress. Sun City, South Africa

5. Lolon S, Brune J, Gilmore R, Bogin J, Grubb J, Saki S, Juganda A (2016) CFD studies on the phenomenon of gob breathing induced by barometric pressure fluctuations. SME Annual Meeting, Phoenix, AZ Preprint 16-154:1-5

6. Marts J, Brune J, Gilmore R, Worrall D, Grubb J (2013) Impact of face ventilation and nitrogen inertization on hazardous gas distribution in bleederless longwall gobs. Min Eng 65(9):71-77

7. Wasilewski S, (2014), "Influence of barometric pressure changes on ventilation conditions in deep mines." Arch. Min. Sci., Vol. 59, No. 3, Warsaw, Poland, p. 621-639
8. Kissell, F.N., (2006). "Handbook for methane control in mining." U.S. Department of Health and Human Services, Public Health Service, Centers for Disease Control and Prevention, National Institute for Occupational Safety and Health, DHHS (NIOSH) Publication No. 2006-127, IC 9486

9. Balusu R, Deguchi G, Holland R, Moreby R, Xue S, Wendt M, Mallett C (2002) Goaf gas flow mechanics and development of gas and sponcom control strategies at a highly gassy mine. Coal Safety 20:35-45

10. Karacan CÖ, (2008). "Modeling and prediction of ventilation methane emissions of U. S. longwall mines using supervised artificial neural networks." National Institute for Occupational Safety and Health, Pittsburgh Research Laboratory, Pittsburgh, PA, 15236, United States. https://www.cdc.gov/niosh/mining/works/ coversheet1790.html. Accessed 05/04/17

11. Ren TX and Edwards JS, (2000), “Three-dimensional computational fluid dynamics modelling of methane flow through permeable strata around a longwall face." Transactions, Institution of Mining and Metallurgy, p. A41-A48

12. Ren T, Balusu R, and Claassen C, (2011). "Computational fluid dynamics modelling of gas flow dynamics in large longwall goaf areas." 35th APCOM Symp. - application of computers and operations res. In the miner. Industry, p. 603-613

13. Schatzel SJ, Karacan CO, Krog RB, Esterhuizen GS, and Goodman $\mathrm{GV}$, (2008), "Guidelines for the prediction and control of methane emissions on longwalls." National Institute for Occupational Safety and Health, DHHS (NIOSH) Publication No. 2008-114, Information Circular 9502, p. 1-83

14. Torano J, Torno S, Menendez M, Gent M, Velasco J (2009) Models of methane behavior in auxiliary ventilation of underground coal mining. Int J Coal Geol 80:35-43

15. Cradle, (2012). Thermofluid analysis system with unstructured mesh generator SC/tetra version 10 user's guide, Software Cradle Co., Ltd.

16. Fluent 5.5, ANSYS, (1997). Copyright fluent Inc., Lebanon, NH

17. Nitao J, (2000). "NUFT, flow and transport code V3.0s." Software Configuration Management, Yucca Mountain Project - STN: 
10088-3.0S-00. Prepared at Lawrence Livermore National Laboratory

18. Pruess K, Oldenburg C, and Moridis G, (1999). "TOUGH2 user's guide, version 2.0.” Report LBNL-43134, Lawrence Berkeley National Laboratory, Earth Sciences Division, Berkeley, California

19. Danko G (2006) Functional or operator representation of numerical heat and mass transport models. ASME J Heat Transfer 128:162-175

20. U.S. Patent No. 7610183B2, (2008), and U.S. Patent No. 8396693 B2 (2013), "Multiphase physical transport modeling method and modeling system"

21. Ventsim Software, (2018). Ventsim Visual ${ }^{\mathrm{TM}}$ user guide version 5.0 in: Chasm Consulting, Brisbane, http://www.ventsim.com

22. Stewart C, Aminossadati S, Kizil M, (2015), "Use of live sensor data in transient simulations of mine ventilation models" International Conference on Fibre-optic and Photonic Sensors for Industrial and Safety Applications 2015

23. Bluhm SJ, Marx WM, Von Glehn FH, and Biffi M, (2001). "VUMA mine ventilation software." J Mine Ventilation Soc South Africa, Vol 54

24. Asante W (2017) Dynamic atmospheric signal analysis for improving mine safety and health. In: Ph.D. dissertation. University of Nevada, Reno, pp 1-167

25. Danko G, (2008). MULTIFLUX V5.0 software documentation qualification documents according to 10 CFR. Part 830, Software tracking number: 1002-5.0-00, Software Management Office, Berkeley National Laboratory, p.1-1007
26. Danko G (2013) Subsurface flow and transport process model for time-dependent mine ventilation simulations. Min Technol 122(3): 134-144

27. Rostami P, (2013). "Ventilation and contaminant simulation with MULTIFLUX," Ph.D. Dissertation, University of Nevada, Reno, Nevada

28. Danko G, (2016), Model elements and network solutions of heat, mass and momentum transport processes. Springer-Verlag $\mathrm{GmbH}$ Germany, ISBN 798-3-662-52929-4, (print); ISBN 798-3-66252931-7 (eBook)

29. Page NG, Caudill SD, Godsey JF, Moore AD, Phillipson SE, Steffey DA, Stoltz, RT, Watkins TR, Cripps DR, Maggard CJ, Morley TA, Sherer HE, Stephan CR, Vance JW, and Brown AL, (2012.) Report of investigation, fatal underground mine explosion, 2010, upper big branch mine-south, performance coal company, Montcoal, Raleight County, West Virginia, ID No. 46-08436. US Dept. of Labor, MSHA, Coal Mine Safety and Health

30. VnetPC (2018) VnetPC (2018). User's manual and tutorial, Mine Ventilation Services, Inc., https://www.mvsengineering.com/files/ NewVNet/VNet.pdf

Publisher's Note Springer Nature remains neutral with regard to jurisdictional claims in published maps and institutional affiliations. 